\title{
Leisure Healthy Green Construction under the Perspective of Symbiosis Theory
}

\author{
Jianping Shu, Denfang Chen, Bin Yang, Xiaoyuan Wen \\ Chengdu Sport University Shichuan University school of public management
}

\begin{abstract}
Under the condition of city leisure sports public service is shortage of supply. We study on urban and rural health green way by using the empirical method and literature method, as well as based on the theory of "mutualism". To think recreational sports is the demand of urban residents and way, healthy green way is tools and coupling of urban and rural areas, and promote integrated urban and rural development and people's health is purpose. Through green construction, it promotes the interaction between the urban and rural, improves recreational space of the city sports need, greatly enrich the urban and rural cultural life, has changed the dual economic structure of urban and rural, promotes the development of local economy. It has played a positive role in building a harmonious society and maintaining social stability. It is a close symbiotic relationship between urban and rural.
\end{abstract} rural

Keywords-healthy green way, development of urban and

\section{PREFACE}

The construction of green way that originated in the second half of the 19th century in the United States, is connecting method by Olmsted advocated, which combined the big park or green space in the coastal river corridor. Green way is the generic terms to connect with a variety of natural and cultural landscape, historical sites of the floorboard of the linear space. It has many functions, such as recreation, transportation, leisure and so on.

Now, our country has serious urbanization and the shortage of urban recreation space, as well as the obvious defects of urban and rural dual structure. City and country need to break the current pattern by social interaction, the construction of healthy green way meet the needs of interaction between urban and rural. The green way, as interactive tools and the link between urban and rural areas, play a more and more important role. According to the theory of "symbiosis", it reached the symbiotic relationship between urban and rural areas as well as man and nature.

\section{HEALTHY GREEN WAY PROMOTES THE HARMONIOUS DEVELOPMENT BETWEEN URBAN AND RURAL AREAS}

\section{A. Health green way strengthens more closely the} symbiotic relationship between urban and rura lareas

Green way combined with slow system, which is throughout the entire city and links the city's green space, park, square and other open spaces. It can be used as places of refuge and relief channel, as well as the life system of the urban. At the same time, Green way united the country's rivers, lakes, pastoral and others linear open spaces. It has changed the bad environment of rural, such as dirty, rotten. Green way built the harmonious living environment which is as "road in the green, in the view of" for urban and rural residents and provided city residents with recreational garden, while improves the living environment and improves the quality of urban life, and also provides a strong motivation for rural development. The construction of greenway and rural reform were simultaneous to promote the infrastructure extension to the rural, to spread urban civilization to the countryside, as well as to strengthen the symbiotic relationship between the two.

\section{B. Health green way promotes the construction and development of leisure sports}

Leisure sports is the mass sports activities which people developed in work, learning, and also is an important part of leisure life, as it to be the beauty of the human spirit home by people created. It is a civilized, healthy and scientific way of leisure life. Leisure spaces and leisure facilities as the most fundamental condition of people in leisure sports activities has an important influence on people's participation in leisure sports activities. In the process of urbanization, leisure sport spaces and leisure sports facilities already can't satisfy people's leisure demand, and restricted the development of leisure fitness activities in city. Therefore, we should to find a scientific and reasonable effective way to increase recreational spaces and leisure facilities.

1) The greenway has changed the way of people's leisure

With the increasingly competition of society, and the accelerating of lives rhythm, as well as the stress, the diseases of civilization are more. The leisure sports as a new way of relaxation are becoming more and more favorable of people. To develop leisure sports activities in the nature is not only to physical exercise to the person, but also to bright the impact on the vision, as well as to make the relaxation of person's body and mind. Green way realizes the symbiosis between urban and rural areas for the construction of leisure, realizes intensive policy space, improves the quality of the national life, and also provides an efficient way for the implementation of the recreational sports. It also makes the sports fitness from relying too much on site, equipment into low dependence of cycling, walking and others greenway sports. This lives way that has advocated green low carbon enriched people's life, residents' life quality. Leisure is subtle changing. 
2) The greenway relieves the shortage of city's leisure sports public space

City is a system which is composed by many factors and specific spaces. With the intensification of urbanization, it has received the serious threat to human survival space, the increasing in both of leisure needs and the developing contradictions of leisure spaces caused greatly, and itself should be a kind of symbiotic relationship between city and nature, also urban and rural. Urban space have to seek breakthrough, green way is a new method to implement the space transfer, to solve the urban leisure space. The greenway organically combines the center and edge of city and village. It is a playground without threshold. Health campaign elements are fully embodied and improved in the green way. Abundant and colorful leisure projects meet the needs of all classes, exercising in the green path is recognized and welcomed by the masses. It promotes the reasonable space layout of city leisure sports.

\section{Richening cultural development in urban and rural areas}

Health and green channel system in bond connecting urban culture and rural culture improves the needs of the modern facilities for urban culture, and implements the mutual infiltration between rural culture and city culture. Rural culture constantly absorbs the city culture and also constantly enriches its content. Urban culture is also constantly absorbing the essence of rural culture. Urban culture and rural culture influence each other, promote each other.

1) The green way becomes the bond of cultural exchange

In the process of urbanization, a large number of historical and cultural essence is missing, the huge threat on the traditional culture. Greenway as the carrier of culture inherits and develops traditional culture. At the same time, the sustainable development of the culture promotes the progress of the greenway system. Through green construction, it breaks the distance between urban and rural areas, and promotes the interaction of the advanced culture and fashion of civilization in between urban and rural areas, it also strengthens the cultural contact between rural and urban areas and promotes the cultural fusion between urban and rural, mutual development, to realize the urban and rural culture as a whole, also to promote the integration of urban and rural. The greenway is the tie that connects urban culture and rural culture to improve the cultural facilities between urban and rural areas.

2) Improving the sustainable development of culture

Culture is a social phenomenon and also a historical phenomenon. Its form is a specific phenomenon through the historical precipitation. It is generic terms that gradually mastered in the process of the human developing purification, to improve the floorboard of the knowledge, ability and habit of human life. Cultural heritage is a kind of non-renewable resources, in China, cultural heritage is disappearing. It plays an important role on the protection of historical culture. Heritage corridor is the combination of the green channel and the regionalization of heritage protection, with their special linear landscape and the collection of culture resources, it is usually with distinct economic center, the booming tourism, adaptive reuse of old buildings, and the improvement of entertainment and environment. City's history and culture is the composition of urban inner quality, the higher tastes and the more energy can show that urban culture has grown up. The mutual integration of human and the environment show the image of the charm city. Greenway, as the carrier of culture, inherits and develops traditional culture. Meanwhile, the sustainable development of the culture promotes the progress of the greenway system.

\section{Stimulating Local Economic Development}

\section{1) Optimizing the industrial structure}

Our country is the urban and rural dual economic structure. In adjusting rural economic structure, the greenway realizes the combination between rural and urban to intensify rural opening to the outside world achieving the growth of the economy. The greenway construction broke the rural economy operation mode running by a single-crop farming to comprehensive, complex operation [3].this is to say that the traditional agriculture is transformed to tourism agriculture, sightseeing agriculture, experiencing agriculture promoting the adjustment of rural industrial structure, the transformation of agricultural industry and realizing the integration between the primary industry and the service sector . And it also Magnifies tourism and forestry, optimizes the industrial structure, promote the interaction and upgrade between traditional agriculture and tourism.

\section{2) Change the traditional tourism mode}

Greenway is an entry point of the development of rural tourism, and we could use the greenway innovative thinking, depend on the needs of the development of the leisure industry and a linear corridor putting the major scenic areas and attractions together to make the village and township construction each has its characteristics of agricultural cultural tourism area. We should combine seasonal difference of Regional development of characteristic agriculture industry. the green way broke the inherent pattern of urban and rural landscape using the most ordinary and economical and productive agricultural wild flowers, weeds, deduce about land in cities, farmers deducing the story of farming culture, interpretation of the concept of "vernacular" landscape to form dislocation model of rural tourism which is seeing flowers in the spring, viewing lotus in the summer, admiring the autumn chrysanthemum appreciation in the autumn, watching yunmei in the winter. Let visitors feel the changing seasons and the farming culture in the history of the last.

3) Promoting economic growth

Putting the greenway construction and development of the rural agriculture together, centering on the tourism six factors of "eating, living, travelling, touring, shopping, 
entertainment" with green as the carrier to promote the development of green economy. At the same time it provides employment opportunities for the development of rural enterprises and local residents, and it also absorbs the rural surplus labor force preventing the rural population to cities, alleviating the pressure of urban population, and rural enterprises also absorb the local farm products changing the traditional rural management pattern, improving farmers' income, promoting rural economy and the socialism new rural construction.

\section{E. Promoting the harmonious development of the society}

With the increase of leisure time, people need a healthy active leisure way to spend their leisure time, and the leisure sport is a healthy, civilized, scientific way of life, because it help people to enjoy leisure independently, improve but bad pastime, restrain and reduce the bad atmosphere in society, advocate healthy and civilized society, maintain social stability and unity, and promote the construction of the rule of law society. The greenway leisure sports achieve the harmonious development between man and nature, build a happy life space, and also maintain the stability and unity of the social situation. Healthy greenway improves the urban and rural dual economic structure, optimize the rural industrial structure, change the rural economic model, transfer the remains in the rural labor force, reduce the unemployment rate, narrow the gap between urban and rural areas, promote the economic growth, and promote rural urbanization. At the same time greenway provides a good place for people to communicate, which is conducive to eliminate the gap, prompt interpersonal relationship be more harmonious, establish a good interpersonal relationship to maintain the social stabile and unite.[4]

\section{F. Promoting urban-rural integration}

To form the orderly, rigorous organization structure, produce the urban and rural economy, the new productivity, the new productivity and make the rural urbanize, we should allocate resources, narrow the gap between urban and rural, optimize the productivity of resources configuration, and rationalize the proportion of different industrial sectors and their rationalization in the configuration of the urban and rural areas. Green way breaks the barrier of the segmentation of greenway construction making logistics, stuff movement, information flow free and reasonable, distribution between urban and rural productivity reasonable, the industrial structure optimized and all kinds of resources can be used efficiently to make difference between urban and rural gradually narrowed.[5]

Healthy green way construction has attracted more and more consumers to come for a visit, so the requirement of consumption quality of target customers increases. for local organic it had the higher request. When it accepts modern civilization, it should change their way of life prompting local delicious to the scale, brand, quality development to improve the economic growth, narrow the differences between urban and rural areas.

\section{CONCLUSION}

Healthy greenway can solve the lack of space of urban leisure sports ,integrate open green space to become public leisure places, which can provide the place for leisure exercise. healthy greenway changed the traditional sports mode, and it has attracted urban mass to the green way to take part in outdoor leisure sports activities actively, which enhances the people's health.

Green way has become a tool and the coupling between the city and the country meeting the needs of the urban and rural interaction. And it realizes the harmonious development of urban and rural, man and nature.

Healthy greenway construction improves the urban and rural dual economic structure, promote economic integration of urban and rural. It created compound and open market which can meet all kinds of needs by making the rural resources and urban market dock adding momentum to the development of regional economy. sharing of Tourism service facilities and infrastructure promotes the improvement of the people's livelihood.

In the construction of healthy greenway, we also should deal with the relationship between the natural environment and humen considering the bearing capacity of the environment, on both sides of the green alien species introduction to balance problems such as easy to destroy the local species.

This article is one of the achievements for national social science fund project "leisure sports public services supply obstacles and paths for research" (11 bty013).

\section{REFERENCES}

[1] Ma Xiangming; CHENG Hongning. Building of greenway system in Guangdong province : conception and innovation. City Planning Review . VOL.37 NO.2 FEB.2013.38-44

[2] Sun Kuili and Lu Yang. Enlighenment of Practice of Greenway Construction Abroad to Tianjin. Journal of Tianjin Academy of Fine 2012.04.73-75

[3] XU Wenhui Reflection and Countermeasures of Greenway Planning and Construction in China. Chinese Landscape Architecture, 2012.06.12-15

[4] XIE Dong xing, Practice, function and concept analysis of greenway sports. Journal of Shandong Institute of Physical Education and Sports Vol.28 No.5 October 2012.11-15

[5] Cai Ying, He Fang, Li Yingyi, Kang Kaishan. Greenway Site Choice with Urban Rural Integration. .2011.9.32-38 